\section{Spread of Neisseria gonorrhoeae resistant to tetracycline outside the United States of America}

Since February 1985 Neisseria gonorrhoeae resistant to tetracycline has been recognised increasingly in the United States of America, 99 isolates from 17 states having been reported by April 1987. ${ }^{1}$ These isolates exhibit high resistance to tetracycline (minimal inhibitory concentration $\geqslant 16 \mathrm{mg}$ tetracycline/l), which is encoded on a 25.2 megadalton transmissible plasmid. ${ }^{2}$ We present what we believe is the first evidence of spread of $N$ gonorrhoeae resistant to tetracycline from the United States and give detailed molecular analysis of these strains.

\section{Case reports}

CASE 1

A 34 year old homosexual Englishman with urethral gonorrhoea was seen in Leeds four weeks after having homosexual intercourse with an unknown man in New York. Fellatio had occurred and he had engaged in passive anal intercourse, the partner using a condom. He had noticed a urethral discharge three days after intercourse. Being a medical auxiliary, he had a stock of tetracycline, which he took for the next three weeks while travelling. The urethral discharge persisted. At diagnosis in Leeds smears and cultures from the rectum and the pharynx were negative for $N$ gonorrhoeae. He was treated with $250 \mathrm{mg}$ ciprofloxacin orally and erythromycin stearate $500 \mathrm{mg}$ twice daily for 10 days. A week later there was no urethral discharge and culture for $N$ gonorrhoeae yielded negative results.

The isolate of $N$ gonorrhoeae from the urethral culture was resistant to tetracycline (minimal inhibitory concentration $16 \mathrm{mg} / \mathrm{l}$ ), moderately sensitive to penicillin (minimum inhibitory concentration $0.32 \mathrm{mg} / \mathrm{l}$ ), and sensitive to erythromycin and ciprofloxacin on disc testing. Examination of the strain showed that two plasmids, of 25.2 and 2.6 megadaltons, were present. ${ }^{3}$ Digestion of plasmid deoxyribonucleic acid with Hind II (isoschizomeric with Hinc II showed the band pattern reported for strains of $N$ gonorrhoeae resistant to tetracycline in the United States. ${ }^{2}$ Auxotype and serotype were determined by standard methods ${ }^{1} ;$ the isolate belonged to class Pro $^{-} / 1 \mathrm{~B}-2$.

\section{CASE 2}

A 27 year old homosexual man presented in Leeds for screening after treatment of rectal gonorrhoea one week previously in London. $N$ gonorrhoeae had been grown from rectal cultures and been found to be sensitive to penicillin on disc testing. Treatment consisted of single oral doses of ampicillin $3 \mathrm{~g}$ and probenecid $1 \mathrm{~g}$. Cultures taken in Leeds showed rectal infection with $N$ gonorrhoeae. The strain was moderately sensitive to penicillin (minimal inhibitory concentration $0.32 \mathrm{mg} / \mathrm{l}$ ), sensitive to spectinomycin (minimal inhibitory concentration $16 \mathrm{mg} / \mathrm{l}$ ), and cefuroxime (minimal inhibitory concentration $0.08 \mathrm{mg} / \mathrm{l}$ ), but resistant to tetracycline (minimal inhibitory concentration $32 \mathrm{mg} / \mathrm{l}$ ). Detailed examination of the strain by the methods described above showed the $25 \cdot 2$ megadalton plasmid, which again belonged to class Pro $^{-} / 1 \mathrm{~B}-2$.

$\mathrm{He}$ returned to London and was treated with spectinomycin $4 \mathrm{~g}$ intramuscularly and co-trimoxazole four tablets twice daily for three days. Two contacts were traced, in whom cultures from all sites were negative for $N$ gonorrhoeae. It was assumed that he had been infected by a casual sexual contact.

\section{Comment}

This report should alert other centres to the spread to the United Kingdom of strains of $N$ gonorrhoeae resistant to tetracycline. The molecular data strongly suggest that the plasmid implicated is related to those of the strains previously described. The auxotype/serotype $\mathrm{Pro}^{-} / 1 \mathrm{~B}-2$ was not described in the most recent report of $\mathrm{N}$ gonorrhoeae resistant to tetracycline in the United States of America, ${ }^{1}$ which indicates further spread of the $25 \cdot 2$ megadalton plasmid among strains. In Germany a strain was found in which the determinant for resistance to tetracycline seemed to be associated with a 10.5 megadalton plasmid. ${ }^{4}$ This highlights the need to determine the genetic basis of resistance to tetracycline in strains of $N$ gonorrhoeae.

The appearance and subsequent international dispersal of $N$ gonorrhoeae resistant to tetracycline resembles the emergence and spread of $N$ gonorrhoeae that produces penicillinase. The probability of selecting strains of $N$ gonorrhoeae resistant to both penicillin and tetracycline should be considered to be high because resistance to these antibiotics is transmissible to sensitive strains of $N$ gonorrhoeae and the determinant of resistance to tetracycline resides on a transposable element. ${ }^{2}$

We are grateful to Dr A G Lawrence and the health advisers in sexually transmitted diseases at the John Hunter Clinic, St Stephen's Hospital, London SW10, for helpful information.
1 Knapp JS, Zenilman JM, Biddle JW, et al. Frequency and distribution in the United States of strains of Neisseria gonorrhoeae with plasmid mediated high level resistance to tetracycline $\mathcal{f}$ Infect Dis 1987;155:819-22.

2 Morse SA, Johnson SR, Biddle JW, Roberts MC. High level tetracycline resistance to Neisseria gonorrhoeae is result of acquisition of streptococcal tet M determinant. Antimicrob Agents Chemother 1986;30:664-70.

3 Bennett PM, Heritage J, Hawkey PM. An ultra-rapid method for the study of antibiotic resistance plasmids. F Antimicrob Chemother 1986;18:421-4.

4 Jahn G, Bialasiewicz AA, Blenk H. Evaluation of plasmids in tetracycline resistant strains of Neisseria gonorrhoeae and Ureaplasma urealyticum in a case of severe urethritis. European fournal of Epidemiology 1985;1:294-300.

(Accepted 1 December 1987)

Department of Genito-Urinary Medicine, General Infirmary, Leeds LS1 3EX

M A WAUGH, MB, DHMSA, consultant physician

C J N LACEY, MB, MRCP, consultant physician

Department of Microbiology, University of Leeds, Leeds LS2 9JT

P M HAWKEY, MD, MRCPATH, consultant microbiologist

J HERITAGE, BA, DPHIL, lecturer

Gonococcus Reference Unit, Bristol Public Health Laboratory, Bristol BS2 8EL

A TURNER, BSC, PHD, principal microbiologist

A E JEPHCOTT, MD, FRCPATH, consultant microbiologist

Correspondence to: Dr Hawkey.

\section{Frequency of attendance at anticoagulant clinics: a prospective study}

The frequency with which patients receiving long term treatment with anticoagulants attend clinics varies considerably among centres. ${ }^{1}$ At this hospital patients receiving treatment with anticoagulants who have a record of good control are seen every 12 weeks, which is twice the interval currently recommended. ${ }^{2}$ We performed a prospective study to assess whether control could be improved by patients attending more frequently.

\section{Patients, methods, and results}

The clinic was held weekly and staffed by a consultant haematologist and a registrar. Of the 690 patients who attended, $87 \%$ were receiving long term treatment. The therapeutic range of international normalised ratio was taken as $2 \cdot 0-4 \cdot 0$ for all patients. The clinic extended the interval between appointments to 12 weeks during the first year of attendance for patients receiving long term treatment in whom control had been stabilised. Two hundred such patients were randomly divided into two equal groups; the groups did not differ in the indication for anticoagulation. One group was monitored routinely every 12 weeks and the other was seen at intervals of six weeks over 40 weeks. For each patient the data from all visits to the clinic were summarised by calculating the mean difference from an ideal international normalised ratio of $3 \cdot 0$ (table).

\begin{tabular}{|c|c|c|}
\hline $\begin{array}{l}\text { Mean difference from } \\
\text { international } \\
\text { normalised ratio } \\
\text { of } 3 \cdot 0\end{array}$ & $\begin{array}{c}\text { Patients seen } \\
\text { every } \\
12 \text { weeks } \\
(n=94)\end{array}$ & $\begin{array}{c}\text { Patients seen } \\
\text { every } \\
\text { six weeks } \\
(\mathbf{n}=85)\end{array}$ \\
\hline $0-0.25$ & 11 & 7 \\
\hline $0 \cdot 26-0.50$ & 26 & 31 \\
\hline $0.51-0.75$ & 25 & 26 \\
\hline $0 \cdot 76-1 \cdot 00$ & 17 & 10 \\
\hline $1 \cdot 01-1 \cdot 25$ & 7 & 2 \\
\hline $1 \cdot 26-1 \cdot 50$ & 4 & 4 \\
\hline$>1.50$ & 4 & 5 \\
\hline
\end{tabular}

There was no significant difference in control with anticoagulants between the two groups (Mann Whitney U test, $\mathrm{p}=0.5157$ ). No episodes of thrombosis or bleeding were recorded in either group during the study. Seventeen patients had their appointments brought forward because of inadequate control (nine in the group seen every 12 weeks, eight in the group seen every six weeks), 21 patients were lost from the study, most commonly because of a change of address, though three patients in the group seen every six weeks asked to return to the 12 week interval for personal convenience. 


\section{Comment}

Improvement in the standardisation of laboratory control of anticoagulation has not been accompanied by similar progress in the quality control of treatment. ${ }^{3}$ Clinical practice varies widely among centres, which have differing therapeutic ranges and frequencies of attendance. ${ }^{1}$ Clinics offering shorter intervals between appointments must balance the potential benefits of close monitoring against the greater cost to the hospital and inconvenience to the patient. Many patients receiving long term treatment with anticoagulants are elderly and require the provision of transport. ${ }^{4}$

In our patients extension of the interval between appointments to 12 weeks had been compatible with good control. ${ }^{1}$ This study suggests that there is no benefit to be derived from monitoring this cohort of patients at shorter intervals. Though all appointment intervals should be under constant review, we found that few patients being seen at intervals of 12 weeks needed to attend more frequently.

The use of an all embracing therapeutic range of international normalised ratio of $2 \cdot 0-4 \cdot 0$ may be criticised. Duxbury observed that control with anticoagulants is likely to be more difficult with the narrower therapeutic ranges that have recently been recommended. ${ }^{5}$ In our view the narrower ranges could safely be introduced for patients with stable control without an unacceptable proportion of patients becoming overtreated.

We thank Dr B E Roberts for permission to report on patients under his supervision.

1 Howard MR, Milligan DW. Frequency of attendance at anticoagulant clinics. Acta Haematol (Basel) 1986;76:78-80.

2 Shinton NK. Guidelines on oral anticoagulation. Glasgow: British Society for Haematology, 1984. (Haemostasis and thrombosis task force report to members.)

3 Loeliger EA. Laboratory control, optimal therapeutic ranges and therapeutic quality control in oral anticoagulation. Acta Haematol (Basel) 1985;74:125-31.

4 Stamp EJ, Jones SJ, Ryrie DR, Hedley AJ. Oral anticoagulants: a cost-effectiveness approach. Journal of the Royal College of Physicians of London 1985;19:105-8.

5 Duxbury BM. Therapeutic quality control leading to further clinical assessment of oral anticoagulation. Acta Haematol (Basel) 1986;76:65-7.

(Accepted 9 December 1987)

Department of Haematology, General Infirmary, Leeds LS1 3EX

M R HOWARD, MRCP, registrar

D W MILLIGAN, MD, MRCPATH, senior registrar

Correspondence to: Dr M R Howard, United Kingdom Transplant Service, Southmead Road, Bristol, BS10 5ND.

\section{Haemolytic uraemic syndrome in adults}

The haemolytic uraemic syndrome is characterised by microangiopathic haemolytic anaemia, acute renal failure, and thrombocytopenia. Most cases occur in children after a prodrome of painful bloody diarrhoea. Absence of this prodrome indicates a poor prognosis. Bacterial pathogens including shigella and salmonella have been associated with the diarrhoeal prodrome in a minority of cases in temperate countries; on routine culture most samples are negative for these pathogens and for campylobacter. Karmali $e$ al found evidence of infection with Escherichia coli that produces verotoxin in 30 of 40 children with the syndrome. ${ }^{1}$ Such $E$ coli can also cause haemorrhagic colitis without the haemolytic uraemic syndrome. It was reported as causing haemorrhagic colitis in 32 of 89 adults and children; only two adults developed the haemolytic uraemic syndrome. ${ }^{2}$ Very few other adult cases of the syndrome have been reported. Neill et al described two young women with a diarrhoeal prodrome who made a complete recovery, ${ }^{3}$ and Ponticelli et al described 11 patients with a poor overall outcome; only one of these had a diarrhoeal prodrome. ${ }^{4}$

Over two years we have seen six patients wtih microangiopathic haemolytic anaemia after a diarrhoeal illness; four developed renal dysfunction. A common pattern of presentation was apparent.

\section{Case reports}

The table gives clinical details of the patients. All six patients had been in good health before admission. All experienced an acute diarrhoeal illness and had bloody stools; four had severe abdominal pain. One patient (case 2), who had had bloody diarrhoea for three weeks before being admitted, presented with lethargy secondary to anaemia. Haemoglobin concentrations fell in all patients, and blood films showed the characteristics of a microangiopathic haemolytic anaemia: fragmented red cells, helmet cells, and thrombocytopenia. The patient who presented with lethargy secondary to anaemia had a marginally raised urea concentration when admitted. Another patient received haemodialysis and regained normal renal function. Patients also received intravenous rehydration, blood products as required, and broad spectrum antibiotics for protracted colitic symptoms. An 85 year old woman (case 6) refused dialysis and died; the remaining five patients recovered completely.

Stool cultures for salmonella, shigella, and campylobacter and examinations for ova, cysts, and parasites uniformly yielded negative results, as did examination for cytotoxin produced by Clostridium difficile. Strain O 157 of $E$ coli producing verotoxin was sought in two patients and was present in both.

\section{Comment}

The haemolytic uraemic syndrome is an uncommon complication of infective diarrhoea. Our cases show that the syndrome may affect adults of all ages. As in children, the prognosis is good when there is a prodrome of diarrhoea and stool culture yields negative results. Haemorrhagic colitis is sometimes seen in infectious disease units, and routine stool cultures usually yield negative results. We suggest that in patients with abdominal pain, bloody diarrhoea, and neutrophilia renal function and haemoglobin concentration should be monitored closely and blood film examined. $E$ coli producing verotoxin should be sought if results of routine cultures are negative and facilities are available. In our cases the microangiopathic haemolytic anaemia varied in severity and was not always associated with severe renal dysfunction. Five of our six patients were women, and it will be interesting to see if this trend continues.

We thank Mr Peter Chapman of Sheffield Public Health Laboratory for identifying and $O$ typing the strain of $E$ coli.

1 Karmali MA, Petric M, Lim C, et al. The association between idiopathic haemolytic uraemic syndrome and infection by verotoxin producing Escherichia coli. $\mathcal{F}$ Infect $D$ is 1985;151:775-82. 2 Smith HR, Rowe B, Gross RJ, Fry NK, Scotland SM. Haemorrhagic colitis and verotoxin producing Escherichia coli in England and Wales. Lancet 1987;i:1062-5.

3 Neill MA, Agosti J, Rosen H. Hemorrhagic colitis with Escherichia coli O157:H7 preceding adult hemolytic uremic syndrome. Arch Intern Med 1985;145:2215-7.

4 Ponticelli C, Rivolta E, Imbascati E, Rossi E, Manucci PM. Hemolytic uremic syndrome in adults. Arch Intern Med 1980;140:353-7.

(Accepted 25 November 1987)

Department of Medicine and Communicable Diseases, Lodge Moor Hospital, Sheffield 10

D J WHITE, MB, MRCP, registrar

F YONG, MB, CHB, senior house officer

$M$ W MCKENDRICK, MB, MRCP, consultant physician

Correspondence to: Dr McKendrick.

Haemoglobin concentration and renal function in adults with haemolytic uraemic syndrome

\begin{tabular}{|c|c|c|c|c|c|c|c|c|c|c|c|c|}
\hline \multirow[b]{2}{*}{ Case No } & \multirow{2}{*}{$\begin{array}{c}\text { Age } \\
\text { (years) } \\
\text { and } \\
\text { sex }\end{array}$} & \multicolumn{5}{|c|}{ Concentrations at admission } & \multicolumn{5}{|c|}{ Peak or trough concentrations } & \multirow{2}{*}{$\begin{array}{l}\text { Time from } \\
\text { onset of illness } \\
\text { to peak or trough } \\
\text { concentrations } \\
\text { (days) }\end{array}$} \\
\hline & & $\underset{(\mathrm{g} / \mathrm{l})}{\text { Haemoglobin }}$ & $\begin{array}{l}\text { White cell } \\
\text { count } \\
\left(\times 10^{9} / 1\right)\end{array}$ & $\begin{array}{c}\text { Platelet } \\
\text { count } \\
\left(\times 10^{9} / 1\right)\end{array}$ & $\begin{array}{c}\text { Urea } \\
(\mathrm{mmol} / \mathrm{l})\end{array}$ & $\begin{array}{c}\text { Creatinine } \\
(\mu \mathrm{mol} / \mathrm{l})\end{array}$ & $\underset{(\mathrm{g} / \mathrm{l})}{\text { Haemoglobin }}$ & $\begin{array}{c}\text { White cell } \\
\text { count } \\
\left(\times 10^{9} / 1\right)\end{array}$ & $\begin{array}{c}\text { Platelet } \\
\text { count } \\
\left(\times 10^{9} / 1\right)\end{array}$ & $\begin{array}{c}\text { Urea } \\
(\mathrm{mmol} / \mathrm{l})\end{array}$ & $\begin{array}{c}\text { Creatinine } \\
(\mu \mathrm{mol} / \mathrm{l})\end{array}$ & \\
\hline 1 & $79 \mathrm{~F}$ & 132 & $16 \cdot 8$ & 138 & $4 \cdot 5$ & 73 & 88 & 36.4 & 68 & $41 \cdot 7$ & 385 & 9 \\
\hline 2 & $58 \mathrm{~F}$ & 60 & $3 \cdot 7$ & 153 & $10 \cdot 4$ & 76 & 60 & $3 \cdot 7$ & 153 & $10 \cdot 4$ & 76 & $21^{\star}$ \\
\hline 3 & $58 \mathrm{~F}$ & 145 & $19 \cdot 2$ & 275 & $18 \cdot 0$ & 134 & 84 & $12 \cdot 4$ & 242 & $20 \cdot 3$ & 208 & 11 \\
\hline 4 & $53 \mathrm{M}$ & 180 & $16 \cdot 5$ & 209 & $5 \cdot 2$ & 97 & 88 & 11.0 & 150 & $21 \cdot 5$ & 261 & 10 \\
\hline 5 & $38 \mathrm{~F}$ & 168 & $28 \cdot 2$ & 270 & $6 \cdot 1$ & 76 & 73 & 18.9 & 90 & $6 \cdot 1$ & 76 & 10 \\
\hline 6 & $85 \mathrm{~F}$ & 140 & $16 \cdot 7$ & 160 & $10 \cdot 4$ & 103 & 89 & 12.9 & 87 & $65 \cdot 1$ & 1094 & $15 \dagger$ \\
\hline
\end{tabular}

*At admission.

†Day of death. 